\title{
COMPLEX TRAUMA, COMPLEX REACTIONS: ASSESSMENT AND TREATMENT
}

\author{
CHRISTINE A. COURTOIS \\ Washington, DC, and Psychiatric Institute of Washington
}

Complex trauma occurs repeatedly and escalates over its duration. In families, it is exemplified by domestic violence and child abuse and in other situations by war, prisoner of war or refugee status, and human trafficking. Complex trauma also refers to situations such as acute/chronic illness that requires intensive medical intervention or a single traumatic event that is calamitous. Complex trauma generates complex reactions, in addition to those currently included in the DSM-IV (American Psychiatric Association, 1994) diagnosis of posttraumatic stress disorder (PTSD). This article examines the criteria contained in the diagnostic conceptualization of complex PTSD (CPTSD). It reviews newly available assessment tools and outlines a sequenced treatment based on accumulated clinical observation and emerging empirical substantiation.

Complex trauma refers to a type of trauma that occurs repeatedly and cumulatively, usually over a period of time and within specific relationships and contexts. The term came into being over the past decade as researchers found that some forms of trauma were much more pervasive and com-

Christine A. Courtois, independent practice, Washington, DC, and The CENTER: Posttraumatic Disorders Program, Psychiatric Institute of Washington, Washington, DC.

Correspondence regarding this article should be addressed to Christine A. Courtois, PhD, 3 Washington Circle, Suite 205, Washington, DC 20037. E-mail: cacourtoisphd@aol.com plicated than others (Herman,1992a, 1992b). The prototype trauma for this change in understanding was child abuse. The expanded understanding now extends to all forms of domestic violence and attachment trauma occurring in the context of family and other intimate relationships. These forms of intimate/domestic abuse often occur over extended time periods during which the victim is entrapped and conditioned in a variety of ways. In the case of child abuse, the victim is psychologically and physically immature-his or her development is often seriously compromised by repetitive abuse and inadequate response at the hands of family members or others on whom he or she relies for safety and protection.

The expanded understanding also extends to other types of catastrophic, deleterious, and entrapping traumatization occurring in childhood and/or adulthood, for example, ongoing armed conflict and combat, POW status, and the displacement of populations through ethnic cleansing, refugee status, and relocation and through human trafficking and prostitution. It might also result from situations of acute and chronic illness that require ongoing and intensive (and often painful) medical intervention or may even result from a single catastrophic trauma, for example, witnessing the sudden traumatic death of another individual or experiencing a brutal gang rape.

\section{Diagnostic Conceptualization of Complex Trauma}

The diagnosis of posttraumatic stress disorder (PTSD) was first included in the third edition of the Diagnostic and Statistical Manual of Mental Disorders (DSM-III; American Psychiatric Association, 1980), largely because of the need for diagnostic nomenclature by which to describe the adverse reactions experienced by combat troops returning from Vietnam. It was derived from the observations and conceptualizations of early re- 
searchers of war trauma (World Wars I and II and the Korean conflict; Kardiner, 1941) and included the symptom triad of reexperiencing, numbing/avoidance, and hyperarousal (American Psychiatric Association, 1980) and a phasic alternation between reexperiencing and numbing described by Horowitz (1976). The diagnosis was welcomed by those researching and treating combat trauma and by other researchers who were beginning to investigate other types of trauma, such as rape, domestic battering, and child abuse and neglect (particularly child sexual abuse/ incest). At the time, these researchers had begun to identify a number of posttraumatic syndromes in the various populations under study: rape trauma syndrome (Burgess \& Holmstrom, 1974), battered woman syndrome (Walker, 1979, 1984), child abuse/sexual abuse trauma (Briere, 1984, 1987; Finkelhor, 1985), and incest trauma (Courtois, 1979a, 1979b; Herman \& Hirschman, 1977). These researchers began to routinely apply the newly available diagnosis of PTSD to the effects they observed in their research and clinical samples.

Another noteworthy inclusion in the third edition of the $D S M$ was diagnostic criteria for dissociative disorders (DDs). The contemporary study of dissociation began during this same time period. Researchers began to find that DDs in children and adults were often related to reported histories of severe child abuse and neglect. Researchers of child abuse and dissociation, respectively, began to realize the crossover between their populations and came to understand that both areas of research involved trauma and posttraumatic reactions. Five different DDs were identified in the DSM-III: fugue, dissociative amnesia, depersonalization disorder, multiple personality disorder, and dissociative disorder, not otherwise specified (American Psychiatric Association, 1980).

Despite the obvious advances that were made at the time in understanding posttraumatic reactions, a number of researchers and clinicians argued that the diagnosis of PTSD was not a perfect fit for the reactions experienced by victims of child abuse and domestic trauma and other populations where traumatization occurred repeatedly and extensively (Briere, 1987, 1992; Courtois, 1988; Finklehor, 1984; Herman, 1992a, 1992b). They noted that the criteria for PTSD had been derived directly from the study of adult male combatants exposed to war trauma. As a result, the reactions of those involved in combat were likely significantly different from those of immature individuals whose exposure to traumatic stress was ongoing and related to family life.

Many researchers conducted factor analyses of the findings of available studies of child abuse trauma (findings summarized in Herman, 1992a, 1992b) and determined that the effects of such trauma, although posttraumatic in nature, were significantly different from PTSD as defined in the DSM-III (American Psychiatric Association, 1980). Individuals exposed to trauma over a variety of time spans and developmental periods suffered from a variety of psychological problems not included in the diagnosis of PTSD, including depression, anxiety, self-hatred, dissociation, substance abuse, self-destructive and risktaking behaviors, revictimization, problems with interpersonal and intimate relationships (including parenting), medical and somatic concerns, and despair. Moreover, these problems were categorized as comorbid conditions rather than being recognized as essential elements of complicated posttraumatic adaptations. Clinicians were discovering that these complex conditions were extremely difficult to treat and varied according to the age and stage at which the trauma occurred, the relationship to the perpetrator of the trauma, the complexity of the trauma itself and the victim's role and role grooming (if any), the duration and objective seriousness of the trauma, and the support received at the time, at the point of disclosure and discovery, and later. Researchers involved in this work proposed an alternative conceptualization, complex PTSD (CPTSD) or "disorders of extreme stress not otherwise specified" (DESNOS; Pelcovitz et al., 1997).

The PTSD committee for DSM-IV authorized a multisite field trial to investigate (a) alternative versions of the PTSD stressor criterion, (b) the validity of the items across stressors, (c) the adequacy of the tripartite division of symptoms, and (d) potential changes in the minimum required PTSD symptoms. An additional goal of the field trial was to examine the feasibility of a constellation of trauma-related symptoms (CPTSD) not addressed by the PTSD diagnosis and the reliability of a structured interview to measure this new conceptualization (Roth, Pelcovitz, Van der Kolk, \& Mandel, 1997). Findings of this field trial, which took place between 1991 and 1992, demonstrated that CPTSD is specific to trauma, is rarely found among nontrauma exposed survivors 
(has a high construct validity), and is comorbid with the diagnosis of PTSD. Follow-up studies examining CPTSD among combat veterans (Ford, 1999; Newman, Orsillo, Herman, Niles, \& Litz, 1995), child abuse victims (Ford \& Kidd, 1998), and battered women (Pelcovitz \& Kaplan, 1995), as well as a study examining responses to fluoxetine (Van der Kolk et al., 1994) found support for the clinical usefulness of the symptom constellation, usefulness further supported by the inclusion of a similar diagnosis in the ICD-10 diagnosis of enduring personality change after catastrophic experience (World Health Organization, 1994). Since these early studies, research on a variety of populations and in a variety of settings has found support for the hypothesis that early interpersonal trauma, especially childhood abuse, predicts a higher risk for developing CPTSD/DESNOS than accidents and disasters (Roth et al., 1997). In a follow-up study of a specialized inpatient population of traumatized individuals, Ford (1999) found that despite substantial overlap between PTSD and DESNOS, the two conditions were substantially different in terms of symptoms and functional impairment. In contrast with the $D S M-I V$ field trial finding of a 92\% comorbidity rate between DESNOS and PTSD, Ford found that DESNOS could occur in the absence of PTSD (Ford, 1999), leading him to suggest that PTSD and DESNOS are fundamentally distinct in that PTSD symptoms do not account for those included in DESNOS. More research is needed to see if this finding holds.

The diagnostic conceptualization of CPTSD/ DESNOS as defined for the field trial consisted of seven different problem areas shown by research to be associated with early interpersonal trauma (Herman, 1992a, 1992b):

1. alterations in the regulation of affective impulses, including difficulty with modulation of anger and self-destructiveness. This category has come to include all methods used for emotional regulation and self-soothing, including addictions and self-harming behaviors that are, paradoxically, often life saving;

2. alterations in attention and consciousness leading to amnesias and dissociative episodes and depersonalization. This category includes emphasis on dissociative responses different than those found in the DSM cri- teria for PTSD. Its inclusion in the CPTSD conceptualization incorporates the findings regarding dissociation that were mentioned earlier, namely, that dissociation tends to be related to prolonged and severe interpersonal abuse occurring during childhood and, secondarily, that children are more prone to dissociation than are adults;

3. alterations in self perception, such as a chronic sense of guilt and responsibility, and ongoing feelings of intense shame. Chronically abused individuals often incorporate the lessons of abuse into their sense of self and self-worth (Courtois, 1979a, 1979b; Pearlman, 2001);

4. alterations in perception of the perpetrator, including incorporation of his or her belief system. This criterion addresses the complex relationships and belief systems that ensue following repetitive and premeditated abuse at the hands of primary caretakers;

5. alterations in relationship to others, such as not being able to trust and not being able to feel intimate with others. Another "lesson of abuse" internalized by victim/survivors is that people are venal and self-serving, out to get what they can by whatever means including using/abusing others;

6. somatization and/or medical problems. These somatic reactions and medical conditions may relate directly to the type of abuse suffered and any physical damage that was caused or they may be more diffuse. They have been found to involve all major body systems;

7. alterations in systems of meaning. Chronically abused individuals often feel hopeless about finding anyone to understand them or their suffering. They despair of ever being able to recover from their psychic anguish.

Support for a diagnosis of CPTSD/DESNOS, although not yet incorporated into the DSM-IV except as an associated feature of PTSD (American Psychiatric Association, 1994), is growing. A number of clinicians have observed over the years that these adult survivors of childhood abuse present with complex symptom pictures, including engaging in many high-risk situations (self-harm, suicidality, risk-taking, addictions, revictimizations) as well as evidencing impair- 
Special Issue: Complex Trauma, Complex Reactions

ments in their ability to regulate their emotions, to avoid revictimization, and to stay connected in a therapeutic relationship. These characteristics most resemble the symptom picture: emotional lability, relational instability, impulsivity, and unstable self-structure associated with borderline personality disorder (BPD; American Psychiatric Association, 1994), a diagnosis that has come to be understood as a posttraumatic adaptation to severe childhood abuse and attachment trauma (Briere, 1984; Herman, Perry, \& van der Kolk, 1989; Kroll, 1993; Van der Kolk, Perry, \& Herman, 1991; Zanarini, 1997). Despite this understanding, the BPD diagnosis has carried enormous stigma in the treatment community where it continues to be applied predominantly to women patients in a pejorative way. Conceptualizing and understanding BPD as a posttraumatic adaptation can assist the clinician in being more empathic and more even-handed. Yet, the treatment of individuals diagnosed with CPTSD/DESNOS or BPD is fraught with complications (Chu, 1992; Linehan, 1993); exposing these patients too directly to their trauma history in the absence of their ability to maintain safety in their lives can lead to retraumatization (Chu, 1998; Courtois, 1999).

In recent years, treatment for patients with the "classic" form of PTSD has increasingly emphasized the use of cognitive-behavioral interventions (CBT), including prolonged exposure (PE) and cognitive restructuring (CR), techniques for which empirical support has become available (Foa, Keane, \& Friedman, 2000a). The findings in support of the effectiveness of these techniques in ameliorating the often refractory symptoms of PTSD are laudable. Unfortunately, the wholesale application of CBT techniques to patients with CPTSD/DESNOS (even those who clearly meet criteria for PTSD) may be problematic and resurfaces some of the problems described in the previous paragraph. In fact, it is not too strong to say that some patients may actually be harmed by the use of these techniques, especially if applied too early in the treatment process without attention to safety and the ability to regulate strong affect (Chu, 1998; Ford, 1999; Ford \& Kidd, 1998).

\section{Assessment and Treatment of Complex Trauma}

What follows is a description of an assessment and treatment model for CPTSD/DESNOS that attends to these concerns and sets out a sequenced course of treatment. It has as its foundation the development of skills for selfmanagement and safety applying cognitive and CBT techniques over the course of treatment. This model now has approximately 20 years of development based largely upon clinical application, observation, and modification. The aim of this article is to provide an overview and update of the treatment model, "the meta model," and to set out the evolving standard of practice in the treatment of this class of conditions (Chu, 1998; Courtois, 1999). Empirical substantiation of various elements of the treatment model has been undertaken just recently (Ford, Courtois, Steele, Van der Hart, \& Nijenhuis, in press); ongoing development of assessment and treatment will certainly rely upon the findings of these and additional studies.

\section{Assessment}

Strategies and instruments for the assessment of traumatized individuals are relatively recent developments in clinical practice. A variety of specialized instruments are now available (Briere, 2004; Carlson, 1997; Courtois, 1995; Wilson $\&$ Keane, 2004) for both posttraumatic and dissociative conditions (Dell, Dalenberg, Frankel, \& Chefetz, 2003). Yet, the assessment of standard forms of PTSD using instruments developed for $D S M-I V$ criteria (American Psychiatric Association, 1994) may unfortunately not cover the complexity of the CPTSD/DESNOS patient, including such issues as developmental aspects of the trauma history, functional and self-regulatory impairment, personal resources and resilience, and patterns of revictimization.

The recommended approach to the assessment of trauma is to embed it within the standard psychosocial assessment conducted at the beginning of treatment. From the point of intake, the clinician should include questions having to do with possible trauma in the individual's past and/or current life and about posttraumatic and/or dissociative symptomatology. The rationale for this recommendation is that a large number of individuals seeking mental health treatment do so for the direct or indirect consequences of traumatization at some point in their history and that individuals who meet diagnostic criteria for PTSD and for DDs are high end users of mental health services and thus are very likely to be presenting for treatment. 
The clinician should not assume, however, that asking about trauma or trauma and dissociative symptoms will automatically result in disclosure. Some individuals with positive histories of trauma are unwilling or unable to disclose early in the process. Disclosure may only occur as the individual comes to know and trust the therapist. Whether the therapist is asking questions about trauma in an initial assessment or later in the treatment process, several guiding principles are to be emphasized. The client must be approached with respect and with the understanding that asking about trauma can be difficult and painful, as can the disclosure of past or current trauma. The issue of empowerment is another important one. The therapist must convey an attitude of openness and must ask questions from a neutral position of inquiry. If and when a trauma history is disclosed, the therapist then must pay careful attention to the individual's condition in-session and afterwards (in the form of delayed reactions), with titration or even cessation of the inquiry if any decompensation occurs. Inquiry about and discussion of trauma details can cause the spontaneous emergence of symptoms in some individuals. The therapist should be aware ahead of time and be prepared to respond in a preventive way. Being sensitive to this range of possible responses conveys several important messages to the potential client-that the emotional content associated with traumatization can be overwhelming and that the therapist recognizes this and gives the individual's safety and welfare precedence over the story.

Finally, specialized assessment might need to be repeated at different points in treatment since posttraumatic and dissociative symptoms might only emerge gradually, often when enough safety is established in the treatment relationship. For, although some of these symptoms are blatant and highly evident, others are very subtle and have as their goal the maintenance of secrecy in the interest of safety. Unfortunately, most clinicians are not trained to recognize these symptoms and so might miss them. Once the clinician does recognize them and/or seeks consultation or training thereafter, he or she is in a much better position to recognize them in the future.

\section{Instruments}

If the therapist utilizes standard psychological instruments in the initial assessment (e.g., Min- nesota Multiphasic Personality Inventory [MMPI], Millon Multiaxial Clinical Inventory [MCMI]), he or she should be aware that, although these instruments may tap many symptom and function domains, they will likely not tap those associated with posttraumatic and dissociative symptomatology. For this reason, it is recommended that the therapist supplement standard instruments with newly developed screening instruments, symptom inventories, and clinical interviews designed to encompass these domains. The following instruments have been developed specifically to assess the symptoms of PTSD and dissociation and have been found to have adequate reliability and validity. A discussion of the use of many of these instruments, alone or in conjunction with more standard instruments used in psychology and psychiatry, and an approach to the evaluation of trauma can be found in works by Briere (2004), Carlson (1997), Wilson and Keane (2004), and Briere and Spinazzola (in press).

Posttraumatic symptoms, PTSD, and CPTSD. The following instruments are recommended at this time: Clinician-Administered PTSD Scale (CAPS; Blake et al., 1996), Impact of Event Scale-Revised (IES-R; Weiss \& Marmar, 1997), Detailed Assessment of Posttraumatic States (DAPS; Briere, 2001), and Posttraumatic Stress Diagnostic Scale (PDS; Foa, 1995). Perhaps the two most useful in the identification of CPTSD are the Trauma Symptom Inventory (TSI), an instrument developed to assess trauma symptoms proper but that assesses domains of the self and relations with others (Briere, 1995; Briere, Elliot, Harris, \& Cotman, 1995), and the Structured Interview for Disorders of Extreme Stress (SIDES), developed for the DSM-IV field trial (Pelcovitz et al., 1997; van der Kolk, 1999; Zlotnick \& Pearlstein, 1997). Additionally, the Inventory of Altered Self Capacities (IASC; Briere, 2000b) assesses difficulties in relatedness, identity, and affect regulation and is therefore very pertinent to this population, as do the Cognitive Distortion Scales (CDS; Briere, 2000a) and the Trauma and Attachment Belief Scale (Pearlman, 2003), measures of trauma-related beliefs and cognitive distortions.

Dissociative symptoms and the DDs. Several instruments are available to measure various aspects and types of dissociation: Dissociative Experiences Scale (DES; Bernstein \& Putnam, 1986; Carlson \& Putnam, 1993), a screening 
rather than a diagnostic instrument that can be used first and then supplemented by other more detailed instruments, such as (and especially) the Multiscale Dissociation Inventory (MDI; Briere, 2002a) and the Somatoform Dissociation Scale (SDQ-20; Nijenhuis, 2000). Because of the often elusive nature of dissociation, a structured interview is often useful. Three are currently available: the Structured Clinical Interview for DSMIV Dissociation Disorders, SCID-D (Steinberg, 1994; the only available interview with psychometric properties), the Office Mental Status Examination for Complex Chronic Dissociative Symptoms and Multiple Personality Disorder (Loewenstein, 1991), and the Dissociative Disorders Interview Schedule (DDIS; Ross et al., 1989).

Results of these assessment instruments and interviews can guide the treatment process, as will be discussed in the second half of this article. Comprehensive assessment of the sort described above gives the clinician some understanding of the individual's symptom picture, defensive and self structure, capacity for emotional selfregulation, functional competence, and relational ability. The clinician should be careful to assess for the individual's strengths and resources, as well, so as not to fall into the countertransference trap of perceiving the individual as a helpless victim. Whenever possible, the therapist wants to call upon and reinforce the individual's capacities; this will serve as a means of empowering the individual and will encourage growth (rather than regression) and an identity based upon functionality rather than debilitation. The therapist must also encourage appropriate dependence and provide a source of secure attachment for the traumatized individual as a base upon which the therapeutic work is conducted (see Dalenberg, this issue; Liotti, this issue).

\section{Treatment}

At the present time, the evolving standard of care for the treatment of PTSD includes psychotherapy supplemented by psychopharmacology (where appropriate and used to relieve posttraumatic symptoms as well as associated symptoms of depression, anxiety, obsessive-compulsive disorder and, on occasion, psychosis, carefully applied according to the needs of the client; Foa, Davidson, \& Frances, 1999; Foa et al., 2000a). It should be noted that medication has not yet been found useful in specifically targeting dissociation, although the amelioration of symptoms of depression and anxiety may lessen the need for dissociative defenses. As discussed above, the use of cognitive-behavioral approaches, particularly exposure therapy, has received the most research substantiation for the treatment of classic forms of PTSD (Foa, Keane, \& Friedman, 2000b). The use of these approaches with the CPTSD patient is just beginning and preliminary findings show some effectiveness (Resick, Nishith, \& Griffin, 2003), yet significant caution is required in adopting this approach without further research. Hybrid models of treatment that combine or sequence strategies in different ways for the CPTSD client are currently under development, for CPTSD alone and in conjunction with chronic mental illness and with substance abuse. Where they have been tested, they have shown promise (Cloitre, 2002; Cloitre, Koenen, Cohen, \& Han, 2002; Korn \& Leeds, 2002; Leeds \& Shapiro, 2000; McDonagh-Coyle, Ford, \& Demment, 2002; Smucker \& Dancu, 1999; Smucker $\&$ Niederee, 1995). Since research efforts are just beginning, these finding should be considered preliminary.

Findings from these various research efforts as well as from clinical observation have suggested that many treatment approaches and strategies from a variety of theoretical perspectives apply to the treatment of the CPTSD population. Treatment is therefore multimodal and transtheoretical, necessitated in large measure by the multiplicity of problems and issues presented by these clients and by the fact that, CPTSD, like PTSD, has biopsychosocial and spiritual components that require an array of linked biopsychosocial treatment approaches. Moreover, CPTSD clients suffer from developmental/attachment deficits and issues, a situation that requires treatment strategies that are focused on ameliorating these deficits in order to advance the rest of the treatment.

The treatment of CPTSD is cued to the diagnostic criteria that the seven areas of impairment described earlier: (a) alterations in the capacity to regulate emotions, (b) alterations in consciousness and identity, (c) alterations in selfperception, (d) alterations in perception of the perpetrator, (e) somatization, (f) alterations in perceptions of others, and ( $\mathrm{g}$ ) alterations in systems of meaning. The treatment approach that is most recommended at the present time is that of 
a meta-model that encourages careful sequencing of therapeutic activities and tasks, with specific initial attention to the individual's safety and ability to regulate his or her emotional state (Chu, 1998; Courtois, 1999; Ford et al., in press; Herman, 1992b; Kluft, 2002; Linehan, 1993). The treatment has a whole-person philosophy that does not overemphasize the traumatic antecedents of the individual's difficulties above all else, yet does give them appropriate emphasis and importance. Gold (2000) has labeled this strategy "not trauma alone," and Courtois and Jay (1998) have labeled it "trauma responsive therapy." The treatment model is highly individualized depending on the client's needs and capabilities and recognizes that different healing patterns and prognoses are likely. Kluft (1994) has labeled this as treatment trajectories and has helpfully devised a rating scale of prognostic factors that generally predict a client's treatment course of low, medium, and high gains. At this time, treatment for CPTSD is recognized as needing to be longer rather than shorter term in duration, because of the self-identity, self-regulatory, and relational deficits that are part of the larger symptom picture. Treatment may be conducted on an ongoing basis or more episodically. Additionally, it has been recognized that it is not unusual to have the resolution of one issue or set of issues precede the emergence of others (Chu, 1998; Courtois, 1999).

\section{Sequencing and Stage-Oriented Treatment}

The consensus or meta-model that is most in use in the contemporary treatment of CPTSD involves stages of treatment that are organized to address specific issues and skills (Courtois, 1999). A model consisting of three stages is widely adopted, following the recommendation made in Herman's influential and pioneering book on CPTSD, Trauma and Recovery (Herman, 1992b). A model similar to this one was originally conceptualized and implemented for the treatment of chronic trauma by the French neurologist, Pierre Janet, at the end of the last century (Janet, 1919/1925; Van der Hart, Brown, $\&$ Van der Kolk, 1989). The early stage of treatment is devoted to the development of the treatment alliance, affect regulation, education, safety, and skill-building. The middle stage, generally undertaken when the client has enough life stability and has learned adequate affect modulation and coping skills, is directed toward the pro- cessing of traumatic material in enough detail and to a degree of completion and resolution to allow the individual to function with less posttraumatic impairment. The third stage is targeted toward life consolidation and restructuring, in other words, toward a life that is less affected by the original trauma and its consequences. These three stages are described below, with the most emphasis on the first stage.

It should be noted that although this metamodel does not prescribe or mandate particular interventions for particular clients, it does serve as a general guideline for the therapist that emphasizes safety, security, and affect regulation as core foundations of treatment. It also emphasizes posttraumatic growth and development and the ability to function in the world and seeks to halt the ongoing decline that is so often a legacy of complex trauma. Posttraumatic growth, described by Tedeschi and Calhoun (1995), involves enough consolidation of the biopsychosocial deficits and dysregulations to allow (a) new learning-especially involving affect identification, expression, and modulation-and (b) skill development that leads, in turn, to higher levels of functioning in different life spheres. Although the model is linear, it is not lockstep. Because posttraumatic decline and developmental deficits are difficult to reverse and because the development of trust requires time and effort, treatment usually proceeds in starts and stops. The model is most usefully conceptualized as a recursive spiral to account for this back and forth nature of what Kepner (1995) described as healing tasks within each stage and the likelihood that clients will advance and relapse as they progress through the various tasks. The model is also modified according to the specific issues that emerge during the initial assessment and later and according to the client's defenses and such internal and external resources as ego strength, an available and stable support network, financial and insurance resources, and so forth.

Stage 1: Pretreatment issues, treatment frame, alliance-building, safety, affect regulation, stabilization, skill-building, education, self-care, and support. This is likely to be the longest stage of the treatment and the most important to its success; thus, it is given the most description. It includes pretreatment issues such as the development of motivation for treatment, informed consent regarding the rules of treatment along with client rights and responsibilities, and education 
about what psychotherapy is about and how to participate most successfully. It also begins the development of the treatment relationship in a way that allows a collaborative alliance over time. Saakvitne and colleagues (Saakvitne, Gamble, Pearlman, \& Lev, 2000) have developed the acronym RICH to highlight the relationship elements that are most important in working with traumatized individuals: respect, information, connection, and hope. The underlying assumption of this treatment model, "Risking Connection," is that the therapeutic relationship provides an opportunity to rework attachment difficulties from the past within the therapeutic context in order to develop greater self-capacities and specific personal and interpersonal skills.

Stage 1 resembles more generic psychotherapy in many ways but, as noted by Courtois (1999),

the patient's posttraumatic aftereffects, including deficits in functioning, victimization-related schema about self and other, and episodes of revictimization, often compound it. For example, the development of the therapeutic alliance, a more or less straightforward process with a nontraumatized patient, is often a daunting challenge with one who has been severely interpersonally victimized. The patient may be beset by shame and anxiety and terrified of being judged and "seen" by the therapist. The therapist, in turn, may be perceived as a stand-in for other untrustworthy and abusive authority figures to be feared, mistrusted, challenged, tested, distanced from, raged against, sexualized, etc., or may be perceived as a standin for the longed-for good parent or rescuer to be clung to, deferred to, and nurtured by, or the two may alternate in unpredictable kaleidoscopic shifts (especially when the patient is highly dissociative and is easily triggered). In a related vein, issues of personal safety and revictimization are typically much more pronounced in this treatment population versus one that is more general. (p. 190)

Some clients never move beyond or complete Stage 1. Others may leave treatment prematurely. It is now recognized that good work in Stage 1 is likely to substantially improve the client's life. Some clients may have no need to move into the latter two stages. The primary emphasis of Stage 1 is personal safety in addition to education, personal and life stabilization, skill-building, and the building of social relationships and support.

Safety is defined broadly and involves real and perceived injury and threats to self and to and from others. Many adult trauma survivors live in unsafe situations and relationships in which they are chronically revictimized and/or create risk and danger to themselves in ongoing conscious or unconscious reenactments of their original trauma. Some have no conceptualization of what it means to be safe and do not believe they can ever be safe. From its inception, treatment must be geared to the modification of such erroneous but trauma-related cognitions. The therapist assists the client to gain control over impulsive behavior, self-destructive thoughts and behaviors, dangerous interpersonal situations, addictions, ongoing dissociation, and intense affect discharges that can result in retraumatization and seeks to replace them with personal safety planning. The latter is an active and collaborative process in which the client agrees to address issues of risk and danger in incremental steps. Such planning teaches the significance of safety and provides the client with alternative means of selfregulation and self-management.

Dissociation involves the alteration of consciousness, memory, personal information, and identity, items that are normally associated and integrated (American Psychiatric Association, 1994). Dissociation can be mild and transient or quite extensive, as seen in cases of ongoing abuse during childhood where it may be the abused child's best way of coping. In adulthood as well as childhood, dissociative defenses-especially those that result in skips in ongoing conscious awareness, identity, and memory-may pose significant impediment to safety, as well as to general functioning. The client who actively dissociates to cope and/or who suffers from a major dissociative disorder has increased levels of risk. The use of dissociation as a primary coping style needs identification, a process that is often impeded by its covert nature and the clinician's failure and/or inability to recognize it. Once it is recognized and identified, clients must learn alternative ways of being in relation to self and to the world. The clinician must be careful not to castigate the dissociative client nor to stigmatize the process. As with other coping skills developed in dire times and events, these skills were initially adaptive. Clients need to be shown how they have become maladaptive and actively taught other means of self-management and selfprotection. The process for clients diagnosed with dissociative identity disorder is more complicated and involves more technical interventions, which are beyond the scope of this article. Numerous resources are available on the treatment of dissociative identity disorder (Brenner, 2001; Kluft, 1996, 2002; Putnam, 1989; Ross, 1997; Schwartz, 2000).

The development of safety may pose a special challenge to the addicted client whose safety may 
be dependent upon becoming substance free. Special treatment programs for addicted survivors of complex trauma are now available and are all predicated upon safety (Miller \& Guidry, 2001; Najavits, 2002; Triffleman, Carroll, \& Kellogg, 1999). In fact, the one developed by Najavits is entitled "Seeking Safety."

Client education is also an integral component of Stage 1 treatment and should begin as early as possible in the process. First of all, education can be used to demystify the process of psychotherapy, something that might be terrifying to the client with CPTSD. Additionally, many traumatized individuals know nothing about trauma, may not label what happened to them as traumatic, and have little or no understanding that their symptoms may be related to their past experiences. Education about trauma and its impact is therefore important and may effectively help a client to understand his or her reactions and to develop increased self-understanding and self-compassion.

Education is also the foundation for teaching specific skills that cover many domains: the identification and regulation of emotional states, personal mindfulness, self-care, life skills, coping skills, problem-solving, social skills, and decision-making. As noted by Gold (2000), these skills are often missing in chronically abusive and neglectful families. This skills-based approach is also promulgated in the dialectic behavior therapy model for borderline clients developed by Linehan (1993) and applicable to the complex trauma client. Education is used throughout the treatment process. The client must be motivated to change and must actively practice what is taught. Affect-regulation and modulation are perhaps the most important selfregulatory skills that the client needs to learn.

Self-care and mind-body issues are related to all of the topics discussed in this section but need a focus in their own right. Many CPTSD clients are alienated from themselves, their general wellbeing, and their bodies (as well as their minds). The mind-body split experienced by these clients is often quite problematic, with the client in a more or less perpetual state of disconnect. As a result, many ignore their bodies, are neglectful regarding wellness and medical concerns, and put themselves at unnecessary risk in a variety of ways. As these issues are identified, the clinician may need to actively engage the client in paying attention to his or her bodily reactions and around planning for general self-care, preventive medicine, and/or actual treatment. Treatment approaches that are "whole person" and that address issues of the body and mind under chronic stress have been developed in recent years to supplement an approach that, until just recently, tended to focus exclusively on the psychological realm (Levine, 1997; Ogden \& Minton, 2000; Rothschild, 2000; Siegel, 1999).

Psychopharmacology is another treatment for the related physical-psychological symptoms. As noted above, combined psychopharmacology and psychotherapy are recommended, including for CPTSD patients. Guidelines for the medical management of PTSD can be found in works by Foa et al. (1999; 2000a) and Friedman (2000; 2001).

Having relationships with others and building support networks are crucial to address in this stage. As discussed earlier, mistrust is a major interpersonal hallmark of many CPTSD clients because of their experience with exploitive and nonprotective individuals. Social/relational deficits and problems have long been identified as a legacy of abuse trauma (Courtois, 1979a, 1979b; Finkelhor, 1990), a recognition that has been given additional emphasis in the past 2 decades by attachment researchers (Siegel, 1999). The insecure style is most associated with childhood abuse trauma and results in children and (later) adults whose attachment styles reflect what they learned in their relationships with primary caretakers: Some are excessively self-sufficient and/ or caretaking of others while others are constantly anxious and insecure. Those who were exposed to the most abusive and disorganized of family backgrounds often develop disorganized/ dissociative attachment styles (i.e., those involving shifting states of identity, emotional lability, shifting relationships with others, self-injury as a means of self-soothing, etc.). Historically, these have been long associated with the diagnosis of borderline personality. Clinicians must work directly with these various styles while providing a secure relational base within the treatment from which to acquire more interpersonal skills, including the ability to negotiate relationships and to develop intimacy with others.

As this discussion of Stage 1 is wrapped up, the reader might be asking what happened to the focus on trauma and does any of it happen in this stage? Although this stage does not specifically focus on trauma processing and resolution, much of the work described above does, either directly 
or indirectly, relate to traumatic antecedents. The major difference between this stage and the next is that, in Stage 1, the traumatic material is addressed predominantly from an educational/ cognitive perspective. The client is educated about trauma, short and long-term posttraumatic responses, and the developmental adaptations found to be associated with chronic and complex forms of trauma. Attachment and trauma-based cognitions are constantly attended to in this stage. Early research by Jehu, Klassen, and Gazan (1985) and more recent research by Roth and colleagues (e.g., Roth \& Batson, 1997) have provided empirical support for this approach. It appears that changing abuse- and/or trauma-related cognitions can resolve negative self-perception to such a degree that the client can becomes less symptomatic.

The client's ongoing symptoms become the basis for determining whether more directed work with the trauma is needed. If the client remains symptomatic and is willing to work more directly on the trauma, treatment proceeds to Stage 2. Informed consent stresses that the trauma resolution work is just that, an attempt to process trauma, resolve impasses, and promote posttraumatic growth in the place of decline. Treatment of traumatic material and memories is in the interest of resolution and not in the interest of making or causing new memories to emerge, although that is something that might happen as the trauma is addressed more directly (Gold \& Brown, 1997). At times, the shift into Stage 2 will be explicitly initiated by the clinician. At other times, it will be due to the collaborative evaluation of the client's need and readiness for trauma processing. At still others, it will proceed rather seamlessly from some of the cognitive work that might move naturalistically to a discussion of feelings associated with the cognitive process. Connecting affectively with the trauma story and the trauma-based cognitions and behaviors within the context of a supportive relationship is a major focus of trauma processing (Fosha, 2003; Neborsky, 2003; Schore, 2003; Solomon \& Siegel, 2003).

Stage 2: Deconditioning, mourning, resolution, and integration of the trauma. Stage 2 utilizes exposure and narrative-based techniques to have the client directly address issues related to the trauma (the objective trauma story involving description of how it occurred, where, with whom, etc., along with the subjective reactions that occurred at the time and afterwards) and relies on the client's utilizing the increased selfregulatory skills developed in Stage 1 without resorting to maladaptive defenses. At the present time, gradual as opposed to prolonged exposure and associated desensitization seem to be the choice most clinicians make, although this might change as more technical development occurs. Whatever exposure or narrative technique is selected, its pace and intensity need to be calibrated so as not to overwhelm. It must match the client's capacity. Briere (2002b) has cautioned clinicians about exceeding what he labels the "therapeutic window," or the client's ability to feel without resorting to and reinstating old destructive behaviors such as self-injury, suicidality, and increased use of dissociation. Equally important in this stage is the clinician's ability to stay with the client, that is, to hear the story in some detail, to provide safety by means of attachment security, and to emotionally resonate with the client.

Whether the processing is formalized and utilizes a specialized approach or technique (e.g., eye movement desensitization and reprocessing, EMDR [Shapiro, 2001], guided imagery [Naperstek, 2004], imaginal rescripting [Smucker \& Niederee, 1995], narrative telling/writing [Pennebaker, 2000], or sensorimotor approaches [Levine, 1997; Rothschild, 2000]) or occurs more naturalistically as the client comes to understand more about past events and their impact, other issues usually emerge that require therapeutic attention. For example, grief and mourning for all that was lost are common, as are strong feelings of shame and rage. Stage 2 work involves processing whatever emotions that emerge to the point of some resolution, in order for symptoms to diminish. During this stage, the client might undertake specific actions to resolve relationships with abusers or others. These might involve such actions as disclosures and discussions, boundary development, separation from or reconnection with others, all from a position of increased awareness and understanding and increased interpersonal as well as self-regulatory skills.

Stage 3: Self and relational development, enhanced daily living. Although Stage 3 can be seen as the culmination of the previous work and as an exciting time of growth (Herman, 1992b), it may also be fraught with difficulty for some trauma survivors who have never had the opportunity for a life that is in the range of normal, even with the emphasis placed on life skills in 
Stage 1. Stage 3 might be a time when the client, building upon the awareness developed in Stage 2 , specifically realizes the dysfunction and pathology of the past as he or she continues to attempt to move beyond its influence. Stage 3 frequently involves work on unresolved developmental deficits and fixations and on fine-tuning the self-regulatory skills developed in Stage 1. Some of the issues that are most in evidence are the development of trustworthy relationships and intimacy, sexual functioning, parenting, career and other life decisions, ongoing decisions/ discussions with abusive others, and so forth. Specific resources are available for many of these issues (Basham \& Miehls, 2004; Bass \& Davis, 1994; Davis, 1991; Davis, 2002; Johnson, 2002; Maltz, 2001). In this stage, as in the others, the clinician continues to provide the secure base from which the client does the work and provides ongoing facilitation of relational learning.

As noted earlier, the intensity and duration of the entire treatment will differ substantially. Some clients require treatment for years or even decades. Others may complete treatment in 6-12 months. The initial focus of safety, affect regulation, and skills development is designed to give all who enter treatment different tools with which to function in the world. At whatever point termination occurs, it poses special issues, stirring up feelings of abandonment, grief, fear, and loss of security. It is best for termination to be as collaborative as possible and to be clearly demarcated. The option should be left open for a return, whether for a check-in, booster, or a return to more sustained treatment. Clients can be prepared for the possibility of developmental triggers or other crises necessitating the need for a return to treatment. Because of the possibility of a patient's return, it is recommended that no dual or outside relationships be developed posttermination (Herman, 1992b).

\section{References}

American Psychiatric Association. (1980). Diagnostic and statistical manual of mental disorders (3rd ed.). Washington, DC: Author.

American Psychiatric Association. (1994). Diagnostic and statistical manual of mental disorders (4th ed.). Washington, DC: Author.

BASHAM, K. K., \& MieHLS, D. (2004). Transforming the legacy: Couple therapy with survivors of childhood trauma. New York: Columbia University Press.

BAss, E., \& DAVIS, L. (1994). The courage to heal: A guide for women survivors of child sexual abuse (3rd ed.). New York: Harper \& Row.
Bernstein, E. M., \& Putnam, F. W. (1986). Development, reliability, and validity of a dissociation scale. Journal of Nervous and Mental Disease, 174, 727-735.

Blake, D. D., Weathers, F. W., Nagy, L. M., Kaloupek, D. G., Charney, D. S., \& Keane, T. M. (1996). The Clinician-Administered PTSD Scale (CAPS). Boston: National Center for PTSD, Boston VA Medical Center.

BRENNER, I. (2001). Dissociation of trauma: Theory, phenomenology, and technique. Madison, CT: International Universities Press.

BRIERE, J. (1984). The effects of childhood sexual abuse on later psychological functioning: Defining a post-sexual abuse syndrome. Paper presented at the Annual Convention of the American Psychological Association, Toronto, Ontario, Canada.

BRIERE, J. (1987). Post-sexual abuse trauma: Data and implications for clinical practice. Journal of Interpersonal Violence, 2, 367-379.

BRIERE, J. (1992). Child abuse trauma: Theory and treatment of the lasting effects. Newbury Park, CA: Sage.

BRIERE, J. (1995). Trauma Symptom Inventory (TSI) professional manual. Odessa, FL: Psychological Assessment Resources.

Briere, J. (2000a). Cognitive Distortions Scale (CDS). Odessa, FL: Psychological Assessment Resources.

Briere, J. (2000b). Inventory of Altered Self Capacities (IASC). Odessa, FL: Psychological Assessment Resources.

BRIERE, J. (2001). Detailed Assessment of Posttraumtic Stress (DAPS). Odessa, FL: Psychological Assessment Resources.

BrIERE, J. (2002a). Multiscale Dissociation Inventory (MDI). Odessa, FL: Psychological Assessment Resources.

BRIERE, J. (2002b). Treating adult survivors of severe childhood abuse and neglect: Further development of an integrative model. In L. Myers, J. Berliner, C. T. Briere, T. Hendrix, C. Reid, \& C. Jenny (Eds.), The APSAC handbook on child maltreatment (2nd ed., pp. 175-202). Newbury Park: Sage.

Briere, J. (2004). Psychological assessment of adult posttraumatic states (2nd ed.). Washington, DC: American Psychological Association.

Briere, J., Elliot, D., Harris, K., \& Cotman, A. (1995). Trauma symptom inventory: Psychometrics and association with childhood and adult victimization in clinical samples. Journal of Interpersonal Trauma, 10, 387-401.

Briere, J., \& Spinazzola, J. (in press). Phenomenology and psychological assessment of complex posttraumatic states. Journal of Traumatic Stress.

Burgess, A. W., \& Holmstrom, L. L. (1974). Rape trauma syndrome. American Journal of Psychiatry, 131, 981-986.

CARLSON, E. B. (1997). Trauma assessments: A clinician's guide. New York: Guilford Press.

Carlson, E. B., \& Putnam, W. (1993). An update on the Dissociative Experiences Scale. Dissociation, 6, 16-27.

Chu, J. A. (1992). The therapeutic roller coaster: Dilemmas in the treatment of childhood abuse survivors. Journal of Psychotherapy Practice and Research, 1, 351-370.

Снu, J. А. (1998). Rebuilding shattered lives: The responsible treatment of complex post-traumatic and dissociative disorders. New York: Wiley.

Cloitre, M. (2002, November). A randomized control trial of phase oriented treatment of childhood abuse survivors with PTSD. Paper presented at the Proceedings of the Annual Convention of the International Society for Traumatic Stress Studies, Baltimore, MD. 
Special Issue: Complex Trauma, Complex Reactions

Cloitre, M., Koenen, K. C., Cohen, L. R., \& Han, H. (2002). Skills training in affective and interpersonal regulation followed by exposure: A phase-based treatment for PTSD related to childhood abuse. Journal of Consulting and Clinical Psychology, 70, 1067-1074.

Courtois, C. A. (1979a). Characteristics of a volunteer sample of adult women who experienced incest in childhood and adolescence. Dissertation Abstracts International, 40A, Nov-Dec, 3194-A.

Courtois, C. (1979b). The incest experience and its aftermath. Victimology: An International Journal, 4, 337-347.

Courtois, C. A. (1988). Healing the incest wound: Adult survivors in therapy. New York: Norton.

Courtois, C. A. (1995). Assessment and diagnosis. In C. Classen \& I. D. Yalom (Eds.), Treating women molested in childhood: A volume in the Jossey-Bass library of current clinical technique (pp. 1-34). San Francisco: Jossey-Bass.

CourToIs, C. A. (1999). Recollections of sexual abuse: Treatment principles and guidelines. New York: Norton.

Courtois, C. A., \& JAY, J. (1998). Trauma responsive therapy: A shift in perspective. Centering: Newsletter of The CENTER: Posttraumatic Disorders Program, 3(5), pp. $1,8$.

DAVIS, L. (1991). Allies in healing: When the person you love was sexually abused as a child. New York: Harper Perennial.

DAVIS, L. (2002). I thought we'd never speak again. New York: HarperCollins.

Dell, P. F., Dalenberg, C. J., Frankel, A. S., \& Chefetz, R. A. (2003, November). A tutorial on clinical assessment of dissociative patients: Creating a standard assessment battery. Paper presented at the Annual Conference of the International Society for the Study of Dissociation, Chicago, IL.

FinkLeHOR, D. (1984). Child sexual abuse: New theory and research. New York: Free Press.

FinKELHOR, D. (1985). The traumatic impact of child sexual abuse: A conceptualization. Journal of Orthopsychiatry, $55,530-541$.

FINKELHOR, D. (1990). Early and long-term effects of child sexual abuse: An update. Professional Psychology: Research and Practice, 21, 325-330.

FoA, E. B. (1995). Posttraumatic Stress Diagnostic Scale $(P D S)$. Minneapolis, MN: National Computer Systems.

FoA, E. B., Davidson, J. R. T., \& Frances, A. (1999). Expert consensus guideline series. The Journal of Clinical Psychiatry, 60 (Suppl. 16, Treatment of Posttraumatic Stress Disorder).

Foa, E. B., Keane, T. M., \& Friedman, M. J. (Eds.). (2000a). Effective treatments for PTSD: Practice guidelines from the International Society for Traumatic Stress Studies. New York: Guilford Press.

Foa, E. B., Keane, T. M., \& Friedman, M. J. (2000b). Introduction. In E. B. Foa, T. M. Keane, \& M. J. Friedman (Eds.), Effective treatment for PTSD (pp. 1-17): New York: Guilford Press.

ForD, J. D. (1999). PTSD and disorders of extreme stress following war zone military trauma: Comorbid but distinct syndromes? Journal of Consulting and Clinical Psychology, 67, 3-12.

Ford, J. D., Courtois, C. A., Steele, K., Van der Hart, O., \& Nisenhuis, E. R. S. (in press). Treatment of complex sequelae of psychological trauma. Journal of Traumatic Stress.
FoRD, J. D., \& KIDD, P. (1998). Early childhood trauma and disorders of extreme stress as predictors of treatment outcome with chronic PTSD. Journal of Traumatic Stress, 11, 743-761.

Fosha, D. (2003). Dyadic regulation and experiential work with emotion and relatedness in trauma and disorganized attachment. In M. F. Solomon \& D. J. Siegel (Eds.), Healing trauma: Attachment, mind, body, and brain (pp. 221-281). New York: Norton.

FriedMAN, M. J. (2000). A guide to the literature on pharmacology for PTSD. PTSD Research Quarterly, 11, 1-7.

FrIEDMAN, M. J. (2001). Allostatic versus empirical perspectives on pharmacotherapy. In J. Wilson, M. J. Friedman, \& J. Lindy (Eds.), Treating psychological trauma \& PTSD. New York: Guilford Press.

GolD, S. N. (2000). Not trauma alone: Therapy for child abuse survivors in family and social context. Philadelphia: Taylor \& Francis.

Gold, S. N., \& Brown, L. S. (1997). Therapeutic responses to delayed recall: Beyond recovered memory. Psychotherapy: Theory, Research, Practice, Training, 34, $182-191$.

Herman, J. L. (1992a). Complex PTSD: A syndrome in survivors of prolonged and repeated trauma. Journal of Traumatic Stress, 5, 377-391.

HeRMAn, J. L. (1992b). Trauma and recovery: The aftermath of violence-From domestic to political terror. New York: Basic Books.

Herman, J. L., \& Hirschman, L. (1977). Father-daughter incest. Signs: Journal of Women in Culture and Society, 2, 735-756.

Herman, J. L., Perry, J. C., \& Van der Kolk, B. A. (1989). Childhood trauma in borderline personality disorder. American Journal of Psychiatry, 146, 490-495.

Horowitz, M. J. (1976). Stress response syndromes. Northvale, NJ: Jason Aronson.

JANET, P. (1925). Psychological healing. New York: Macmillan. (Original published 1919)

Jehu, D., Klassen, C., \& Gazan, M. (1985). Cognitive restructuring of distorted beliefs associated with childhood sexual abuse. Journal of Social Work and Human Sexuality, 4, 49-69.

JoHnson, S. (2002). Emotionally focused couple therapy with trauma survivors: Strengthening attachment bonds. New York: Guilford Press.

KARDINER, A. (1941). The traumatic neuroses of war [Monograph]. In Psychosomatic Medicine. Washington, DC: National Research Council.

KePneR, J. I. (1995). Healing tasks: Psychotherapy with adult survivors of childhood abuse. San Francisco: Jossey-Bass.

KLUFT, R. P. (1994). Treatment trajectories in multiple personality disorder. Dissociation, 7, 63-76.

KLufT, R. P. (1996). Outpatient treatment of dissociative identity disorders and allied forms of dissociative disorders not otherwise specified in children and adolescents. Child and Adolescents Psychiatric Clinics of North America, 5, 471-494.

KLuft, R. P. (2002). The difficult to treat patient with a dissociative disorder. In J. M. Dewan \& R. W. Pies (Eds.), The difficult-to-treat psychiatric patient (pp. 209-242). Washington, DC: American Psychiatric Press.

Korn, D., \& LeEDS, A. M. (2002). Preliminary evidence of efficacy for EMDR resource development and installation in the stabilization phase of treatment of complex posttrau- 


\section{Courtois}

matic stress disorder. Journal of Clinical Psychology, 58, $1465-1487$.

KrolL, J. (1993). PTSD/borderlines in therapy: Finding the balance. New York: Norton.

LeEdS, A. M., \& Shapiro, F. (2000). EMDR and resource installation: Principles and procedures for enhancing current functioning and resolving traumatic experiences. In J. Carlson \& L. Sperry (Eds.), Brief therapy strategies with individuals and couples (pp. 469-534). Phoenix, AZ: Zeig, Tucker \& Thisen.

LEvine, P. A. (1997). Waking the tiger: Healing trauma. Berkeley, CA: North Atlantic Books.

LinEHAN, M. (1993). Cognitive-behavioral treatment of borderline personality disorder. New York: Guilford Press.

LOEWENSTEIN, R. J. (1991). An office mental status examination for complex chronic dissociative symptoms and multiple personality disorder. Psychiatric Clinics of North America, 14, 567-604.

MaLtz, W. (2001). The sexual healing journey: A guide for survivors of sexual abuse. New York: Quill.

McDonagh-Coyle, A., Ford, J. D., \& Demment, C. (2002, November). Development and initial evaluation of brief integrative therapy. Paper presented at the International Society for Traumatic Stress Studies, Baltimore, MD.

Miller, D., \& Guidry, L. (2001). Addictions and trauma recovery: Healing the body, mind \& spirit. New York: Norton.

NAPERSTEK, B. (2004). Invisible heroes: Survivors of trauma and how they heal. New York: Bantam.

NAJAVITS, L. (2002). Seeking safety: A treatment manual for PTSD and substance abuse. New York: Guilford Press.

NeBorsky, R. J. (2003). A clinical model for the comprehensive treatment of trauma using an affect experiencingattachment theory approach. In M. F. Solomon \& D. J. Siegel (Eds.), Healing trauma: Attachment, mind, body, and brain (pp. 282-321). New York: Norton.

Newman, E., Orsillo, S. M., Herman, D. S., Niles, B. L., \& LiTZ, B. (1995). The clinical presentation of disorders of extreme stress in combat veterans. Journal of Nervous and Mental Disease, 183, 664-668.

NiJENHUIS, E. (2000). Somatoform dissociation: Major symptoms of dissociative disorders. Journal of Trauma and Dissociation, 1, 7-32.

Ogden, P., \& Minton, K. (2000). Sensorimotor psychotherapy: One method for processing trauma. Traumatology, 6(3), Article 3. Available at http://www.fsu.edu/ trauma/ v6i3/v6i3a3.html

Pearlman, L. A. (2001). The treatment of persons with complex PTSD and other trauma-related disruptions of the self. In J. P. Wilson, M. Friedman, \& J. Lindy (Eds.), Treating psychological trauma and PTSD (pp. 205-236). New York: Guilford Press.

Pearlman, L. A. (2003). Trauma and Attachment Belief Scale (TABS) manual. Los Angeles: Western Psychological Services.

Pelcovitz, D., \& Kaplan, S. (1995, July). Psychological characteristics of battered women: Complex posttraumatic stress disorder in partner abuse. Paper presented at the Family Violence Conference, Durham, NH.

Pelcovitz, D., Van der Kolk, B. A., Roth, S., Mandel, F. S., Kaplan, S., \& Resick, P. A. (1997). Development of a criteria set and a structured interview for disorders of extreme stress (SIDES). Journal of Traumatic Stress, 10, 3-17.
PennebaKeR, J. W. (2000). The effects of traumatic disclosure on physical and mental health. In J. Violante \& D. Paton (Eds.), Posttraumatic stress intervention (pp. 97-114). Springfield, IL: Charles C Thomas.

Putnam, F. W. (1989). Diagnosis and treatment of multiple personality disorder. New York: Guilford Press.

Resick, P. Nishith, P., \& Griffin, M. (2003). How well does cognitive-behavioral therapy treat symptoms of complex PTSD? An examination of child sexual abuse survivors within a clinical trial. CNS Spectrums, 8, 340-343, 351-355.

Ross, C. A. (1997). Dissociative identity disorder: Diagnosis, clinical features, and treatment of multiple personality. New York: Wiley.

Ross, C. A., Heber, S., Norton, G. R., Anderson, D., Anderson, G., \& BARChEt, P. (1989). The Dissociative Disorders Interview Schedule: A structured interview. Dissociation, 2(3), 169-189.

Roth, S., \& BATson, R. (1997). Naming the shadows: A new approach to individual and group psychotherapy for adult survivors of childhood incest. New York: Free Press.

Roth, S., Pelcovitz, D., VAn der Kolk, B. A., \& Mandel, F. (1997). Complex PTSD in victims exposed to sexual and physical abuse: Results from the DSM-IV field trials for posttraumatic stress disorder. Journal of Traumatic Stress, $10,539-555$.

RothSCHILD, B. (2000). The body remembers: The psychophysiology of trauma and trauma treatment. New York: Norton.

Saakvitne, K. W., Gamble, S. G., Pearlman, L. A., \& Lev, B. (2000). Risking connection: A training curriculum for working with survivors of childhood abuse. Lutherville, MD: Sidran Foundation Press.

SCHORE, A. N. (2003). Affect regulation and the repair of the self. New York: Norton.

Schwartz, H. L. (2000). Dialogues with forgotten voices: Relational perspectives on child abuse trauma and treatment of dissociative disorders. New York: Basic Books.

SHAPIRO, F. (2001). Eye movement desensitization and reprocessing: Basic principles, protocols, and procedures. New York: Guilford Press.

SIEGEL, D. J. (1999). The developing mind: Toward a neurobiology of interpersonal experience. New York: Guilford Press.

SMUCKer, M. R., \& Dancu, C. V. (1999). Cognitive-behavioral treatment for adult survivors of childhood trauma: Imagery rescripting and reprocessing. Northvale, $\mathrm{NJ}$ : Jason Aronson.

SmucKer, M. R., \& Niederee, J. (1995). Treating incestrelated PTSD and pathogenic schemas through imaginal exposure and rescripting. Cognitive and Behavioral Practice, 2, 63-93.

Solomon, M., \& Siegel, D. (2003). Healing trauma: Attachment, mind, body, and brain. New York: Norton.

STEINBERG, M. (1994). Interviewer's guide to the Structured Clinical Interview for DSM-IV Dissociative DisordersRevised (SCID-D-R). Washington, DC: American Psychiatric Press.

Tedeschi, R. G., \& Calhoun, L. G. (1995). Trauma and transformation: Growing in the aftermath of suffering. Thousand Oaks, CA: Sage.

Triffleman, E., Carroll, K., \& KellogG, S. (1999). Substance dependence posttraumatic stress disorder therapy: 
An integrated cognitive behavioral approach. Journal of Substance Abuse Treatment, 17, 3-14.

VAn der Hart, O., Brown, P., \& VAN der Kolk, B. A. (1989). Pierre Janet's treatment of post-traumatic stress. Journal of Traumatic Stress, 2, 379-395.

VAN DER KOLK, B. A. (1999). The self-report inventory for disorders of extreme stress (SIDES-SR). Unpublished manuscript.

VAn der KolK, B. A., Dreyfuss, D., Michaels, M., Shera, D., Berkowitz, R., Fisler, R., \& Saxe, G. (1994). Fluoxetine in posttraumatic stress disorder. Journal of Clinical Psychiatry, 55, 517-522.

VAn der Kolk, B. A., Perry, J. C., \& Herman, J. L. (1991). Childhood origins of self-destructive behavior. American Journal of Psychiatry, 148, 1665-1671.

Walker, L. E. (1979). The battered woman. New York: Harper \& Row.
WALKER, L. E. (1984). The battered woman syndrome. New York: Springer.

Weiss, D. S., \& Marmar, C. R. (1997). The Impact of Event Scale-Revised. In J. P. Wilson and T. M. Keane (Eds.), Assessing psychological trauma and PTSD (pp. 399-411). New York: Guilford Press.

Wilson, J. P., \& KeAne, T. M. (2004). Assessing psychological trauma and PTSD (2nd ed.). New York: Guilford Press.

World Health Organization. (1994). The ICD-10 classification of mental and behavioral disorders: Clinical descriptions and diagnostic guidelines. Geneva, Switzerland: Author.

ZANARINI, M. C. (Ed.). (1997). Role of sexual abuse in the etiology of borderline personality disorder. Washington, DC: American Psychiatric Press.

Zlotnick, C., \& Pearlstein, T. (1997). Validation of the Structured Interview for Disorders of Extreme Stress. Comprehensive Psychiatry, 38, 243-247.

\section{E-Mail Notification of Your Latest Issue Online!}

Would you like to know when the next issue of your favorite APA journal will be available online? This service is now available to you. Sign up at http://watson.apa.org/ notify/ and you will be notified by e-mail when issues of interest to you become available! 